\title{
Uroporphyrinogen Decarboxylase: A Splice Site Mutation Causes the Deletion of Exon 6 in Multiple Families with Porphyria Cutanea Tarda
}

James R. Garey, Lyle M. Harrison, Kerry F. Franklin, Kathy M. Metcalf, Evette S. Radisky, and James P. Kushner Division of Hematology, University of Utah School of Medicine, Salt Lake City, Utah 84132

\begin{abstract}
Uroporphyrinogen decarboxylase (URO-D) is a cytosolic heme-biosynthetic enzyme that converts uroporphyrinogen to coproporphyrinogen. Defects at the uroporphyrinogen decarboxylase locus cause the human genetic disease familial porphyria cutanea tarda. A splice site mutation has been found in a pedigree with familial porphyria cutanea tarda that causes exon 6 to be deleted from the mRNA. The intron/exon junctions on either side of exon 6 fall between codons, so the resulting protein is shorter than the normal protein, missing only the amino acids coded by exon 6 . The shortened protein lacks catalytic activity, is rapidly degraded when exposed to human lymphocyte lysates, and is not detectable by Western blot analysis in lymphocyte lysates derived from affected individuals. The mutation was detected in five of 22 unrelated familial porphyria cutanea tarda pedigrees tested, so it appears to be common. This is the first splice site mutation to be found at the URO-D locus, and the first mutation that causes familial porphyria cutanea tarda to be found in more than one pedigree. ( $J$. Clin. Invest. 1990. 86:1416-1422.) Key words: point mutation - exon skipping • polymerase chain reaction - genetic disease • heme biosynthesis
\end{abstract}

\section{Introduction}

Uroporphyrinogen decarboxylase (URO-D) ${ }^{1}$ is the fifth enzyme in the heme biosynthetic pathway and catalyzes the removal of four carboxyl groups from uroporphyrinogen to form coproporphyrinogen. The carboxyl groups are removed in a stepwise fashion from the acetate moiety of each of the pyrrole rings that make up the porphyrin macrocycle (1). The mechanism and number of catalytic sites are unknown, but models have been proposed with from one to four active sites (2-4). Unlike other decarboxylases, no cofactors are involved in catalysis (1). The cDNA and gene for human URO-D have been isolated and sequenced $(5,6)$. The human enzyme is a single polypeptide of 367 amino acids with a molecular weight of 40,831

This work was presented in part at the 1989 meeting of the American Society of Hematology and in abstract form (1989. Blood. 74:44a). Address correspondence and reprint requests to James R. Garey. 1990.

Received for publication 3 May 1990 and in revised form 29 June

1. Abbreviations used in this paper: EB, Epstein-Barr; f-PCT, familial porphyria cutanea tarda; HEP, hepatoerythropoeitic porphyria; PCR, polymerase chain reaction; URO-D, uroporphyrinogen decarboxylase.

J. Clin. Invest.

(C) The American Society for Clinical Investigation, Inc.

$0021-9738 / 90 / 11 / 1416 / 07 \quad \$ 2.00$

Volume 86, November 1990, 1416-1422
Two human diseases, familial porphyria cutanea tarda (fPCT) and hepatoerythpoeitic porphyria (HEP), are associated with inherited defects of URO-D $(7,8)$. In f-PCT, the defect is inherited as an autosomal dominant trait and URO-D activity is usually half-normal in all tissues both by immunoreactive and catalytic assays. In HEP, URO-D activity is usually 5-10\% normal and the disorder is due to the inheritance of mutant alleles from each parent (8). The dermal photosensitivity and uroporphyrinuria characteristic of both diseases are more pronounced in HEP than in f-PCT. A point mutation in the coding region of the URO-D gene has been identified in HEP (281 gly $\rightarrow$ glu, reference 8 ), which produces a catalytically active but unstable protein. We previously described a point mutation in a family with f-PCT. The mutation resulted in a single amino acid change at position 281 , but the substitution (281 gly $\rightarrow$ val, reference 9) was different from the one described in HEP. This mutation also resulted in a catalytically active but unstable protein. The $281 \mathrm{gly} \rightarrow$ val mutation could not be identified in other pedigrees with $\mathrm{f}-\mathrm{PCT}$ suggesting that f-PCT, like HEP, is genetically polymorphic (9).

Northern and Southern blotting experiments (10) have shown that there are no major deletions or rearrangements at the URO-D locus in families with f-PCT and that URO-D mRNA is present in normal amounts (11). The URO-D gene is $\sim 3 \mathrm{~kb}$ in length and includes 10 exons (6). We describe here the characterization of a point mutation that causes the deletion of exon 6 from URO-D mRNA derived from a previously described pedigree with $\mathrm{f}-\mathrm{PCT}$ (pedigree A, reference 11). This point mutation was identified in five of 22 unrelated pedigrees with f-PCT.

\section{Methods}

cDNA synthesis, PCR amplification, cloning, and sequence analysis. Guanidine $\mathrm{HCl}$ was used to extract total RNA from Epstein-Barr (EB) virus transformed lymphocytes derived from the proband (11). $2 \mu \mathrm{g}$ of total RNA were used as a template for single-stranded cDNA synthesis (12), and $1 / s$ of the resulting cDNA was used as template for PCR amplification (13). Numbering of URO-D cDNA follows that of Romeo et al. (5). Two oligonucleotides were used to prime the PCR. The first (5'-CCGGAATTCAGACAGCTGACCATGGAAGCG-3') corresponds to the extreme 5 ' region of URO-D mRNA (nucleotides 7-27 of the original URO-D cDNA sequence in reference 5) with the addition of an Eco RI linker sequence to the $5^{\prime}$ end. The second oligonucleotide (5'-CCCAAGCTTCGATCAATCATCTGTGTTAGT-3') corresponds to the opposite strand in the $3^{\prime}$ untranslated region (nucleotides 1148-1168) with the addition of an Hind III linker sequence. The PCR amplification reactions were carried out in a thermal cycler (Perkin-Elmer Corp., Norwalk, CT) 30 times $\left(1 \mathrm{~min}\right.$ at $90^{\circ} \mathrm{C}$ denature, $1 \mathrm{~min}$ at $55^{\circ} \mathrm{C}$ anneal, $3 \mathrm{~min}$ at $70^{\circ} \mathrm{C}$ extension). An aliquot of the PCR products were analyzed by electrophoresis on $1 \%$ agarose gels, and the remaining material was digested with Hind III and Eco RI and cloned into pBluescript KS. Sequencing was carried out completely in both directions by the chain termination method (14) from pBluescript using a variety of custom oligonucleotide primers with Sequenase (US 
Biochemical Corp., Cleveland, $\mathrm{OH}$ ). Genomic DNA derived from the proband was PCR amplified as above but using different oligonucleotides. The first (5'-CCGGAATTCGAAGAGCAGGACCTAGAAGCG-3', nucleotides 358-378) corresponds to the middle of exon 4 with the addition of an Eco RI linker sequence) and the second (5'CCCAAGCTTGGCCACATCACGGATGTAAGG-3', nucleotides 720-740) corresponds to the opposite strand in the middle of exon 7 , with the addition of an Hind III linker sequence. The amplified DNA was cloned and sequenced as described above.

Northern analysis. 20- $\mu \mathrm{g}$ samples of total RNA derived from EBtransformed lymphoblasts from either normal or affected members of the pedigree were electrophoresed in $1 \%$ agarose gels containing formaldehyde (15). The RNA was transferred to nitrocellulose membranes and subjected to hybridization by ${ }^{32} \mathrm{P}$-labeled (16) URO-D cDNA at $42^{\circ} \mathrm{C}$. The filters were washed at room temperature in $2 \times$ SSC, $0.1 \%$ SDS two times for $30 \mathrm{~min}$, and at $60^{\circ} \mathrm{C}$ two times for $30 \mathrm{~min}$ in $0.2 \times$ SSC, $0.1 \%$ SDS. The filters were exposed to $x$-ray film for $3 \mathrm{~d}$ with an intensifying screen.

Screening other individuals for the mutation. Genomic DNA from three normal individuals, nine affected members from the same pedigree, and 21 unrelated affected individuals were PCR amplified as described above. The amplified products were slot-blotted to nitrocellulose filters and hybridized with a ${ }^{32} \mathrm{P}$-labeled oligonucleotide that contained the mutation (5'-GTGCCCAGCTGAGTCCT-3', the exon 6-intron 6 junction, see Results) as described previously (9). The blots were stripped and rehybridized with a normal probe (5'-GTGCCCAGGTGAGTCCT-3'). Hybridization and washing conditions were as previously described (9).

In vitro degradation studies. RNA was made by transcribing cDNAs from pBluescript $\mathrm{KS}$ in vitro using T7 RNA polymerase after linearization of the plasmid with Eco RI (17). ${ }^{35} \mathrm{~S}$-Methionine-labeled URO-D was translated from RNA transcripts of cloned normal and mutant cDNA (9) using rabbit reticulocyte lysates (Promega Biotec, Madison, WI). $6 \mu$ l of the translation mix was added to $160 \mu$ l of lysate $(6 \mathrm{mg} / \mathrm{ml}$ protein) from lymphoblasts derived from the proband, and aliquots of $20 \mu \mathrm{l}$ were removed after $0,4,8,12$, and $16 \mathrm{~h}$ of incubation at $37^{\circ} \mathrm{C}(9)$. The samples were electrophoresed on $10 \%$ SDS gels (18) and the amount of labeled URO-D quantified at each time point by densitometry of the autoradiogram.

Bacterial expression of URO-D $C D N A$. URO-D cDNAs representing the normal allele and the mutant allele were cloned directionally into the bacterial expression vector pKK233-2, containing the trc promotor (19). The plasmids were then transformed into $E$. coli strain JM101 which were grown in Luria-Bertani medium containing ampicillin to an optical density at $600 \mathrm{~nm}$ of 0.4 , and induced by the addition of IPTG to a final concentration of $0.1 \mathrm{mM}$. The cells were grown an additional $3 \mathrm{~h}$ and harvested.

Western blotting. Bacterial pellets containing recombinant human URO-D were prepared by washing the pellet from a $10-\mathrm{ml}$ culture in $10 \mathrm{mM}$ Tris- $\mathrm{HCl}, \mathrm{pH} 7.5,5 \mathrm{mM} \mathrm{MgCl}_{2}$, resuspending the pellet in 200 $\mu \mathrm{l}$ of the same buffer and boiling for $3 \mathrm{~min}$. The lysates were cooled on ice and treated with $10 \mu \mathrm{l}$ of $1 \mathrm{mg} / \mathrm{ml}$ DNAase I for $15 \mathrm{~min}$ at $20^{\circ} \mathrm{C}$ and $50 \mu 1$ of $4 \times$ SDS sample loading buffer (18) added. Samples were boiled for $2 \mathrm{~min}$ and $40 \mu \mathrm{l}$ of each was electrophoresed for $4 \mathrm{~h}$ in $10 \%$ SDS gels at a constant current of $40 \mathrm{~mA}$. Western blotting was carried out and URO-D was visualized by autoradiography of the blots after processing with a rabbit anti-human-URO-D serum and ${ }^{125}$ I-labeled protein $A$ (20). Western blots were carried out in a similar manner from total protein recovered after lysis of EB virus transformed lymphoblasts derived from affected and unaffected members of the pedigree.

URO-D activity measurements. URO-D catalytic activity was determined using two different substrates, uroporphyrinogen I and pentacarboxyporphyrinogen I as previously described $(11,21)$. Bacterial pellets containing human mutant, normal, or no recombinant URO-D (see above) were lysed by the use of an X-press (AB BIOX; Jarfalla, Sweden), the lysate cleared by centrifugation at $14,000 \mathrm{~g}$ for $20 \mathrm{~min}$ at $4^{\circ} \mathrm{C}$, and the total protein determined (22). $0.3 \mathrm{mg}$ total protein was used for each assay. Porphyrins from the assay were analyzed by HPLC, and nanomoles of decarboxylated porphyrins calculated. All results are given as nanomoles of decarboxylated porphyrins per micrograms total protein per hour. The assays cannot distinguish activity of recombinant human URO-D from that of native bacterial URO-D so assays were done on bacterial lysates which did not contain the expression vector as a control.

\section{Results}

URO-D cDNAs derived from an affected member of a f-PCT pedigree were polymerase chain reaction (PCR) amplified and revealed two sizes of URO-D cDNA upon agarose gel electrophoresis (Fig. $1 A$ ). Northern analysis was carried out on total RNA from both normal and affected individuals and the results suggested that the size difference found in the PCRamplified cDNA was also present in the mRNA. The limited resolution of formaldehyde-agarose gels used for northern analysis, however, did not clearly separate the two URO-D mRNA species (Fig. $1 B$ ). The PCR amplified URO-D cDNA was then cloned into pBluescript, and plasmid DNA purified from individual clones used as template for sequencing. Sequence analysis of eight individual clones revealed that three clones contained a deletion of 162 bases from positions 491-655. This corresponded exactly to exon 6 of the URO-D gene (Fig. 2). Several clones of each size were sequenced to determine if possible point mutations were due to PCR errors or were real mutations. No new point mutations were found in either allele, although several silent mutations and an $A \rightarrow G$ change at position 325 (resulting in a ser $\rightarrow$ gly substitution found in other normal URO-D cDNAs, reference 9) were noted in both alleles.

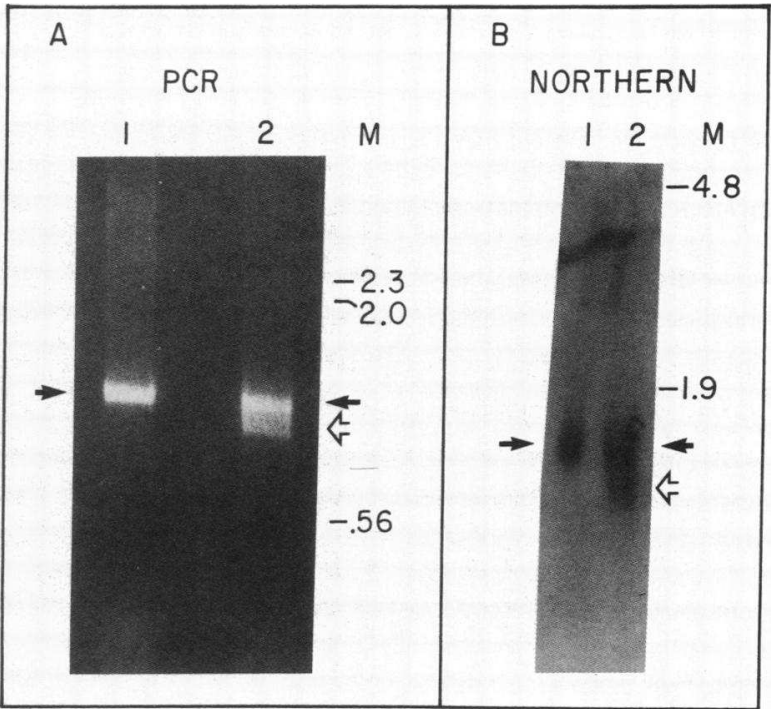

Figure 1. (A) PCR amplification products of cDNA derived from lymphoblasts of a normal (lane 1 ) and affected individual (lane 2) were electrophoresed on a $1 \%$ agarose gel and visualized by ultraviolet fluorescence. Solid arrows indicate the normal size cDNA; open arrow indicates the abnormal cDNA. Lane $M$ indicates molecular weight markers in kilobases. $(B)$ Northern blot of total RNA derived from a normal (lane 1) and an affected individual (lane 2). Solid arrows indicate the normal size message; open arrow indicates the abnormal message. Lane $M$ shows the position of molecular weight markers in kilobases. 


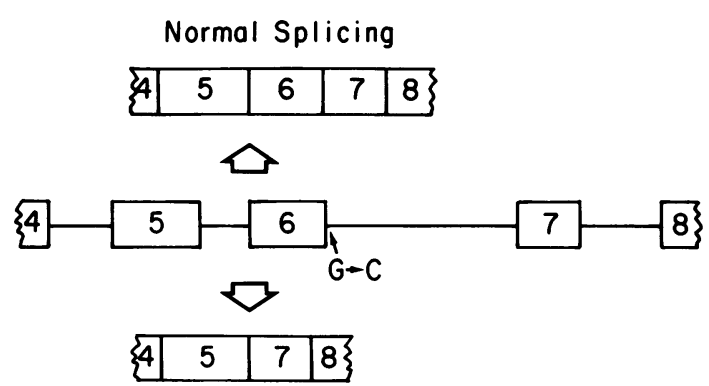

Abnormal Splicing

Figure 2. Normal and abnormal splicing patterns of URO-D premRNA. The position of the $\mathrm{G} \rightarrow \mathrm{C}$ mutation at the $5^{\prime}$ end of intron 6 is indicated.

PCR amplification was carried out using oligonucleotide primers specific for the URO-D gene from the middle of exon 5 to the middle of exon 7. The PCR products were cloned and sequence analysis of individual clones indicated that three of the clones were completely normal at their intron-exon junctions while five contained a $\mathrm{G} \rightarrow \mathrm{C}$ point mutation at the first position of the $5^{\prime}$ end of intron 6 (Fig. 3 ).

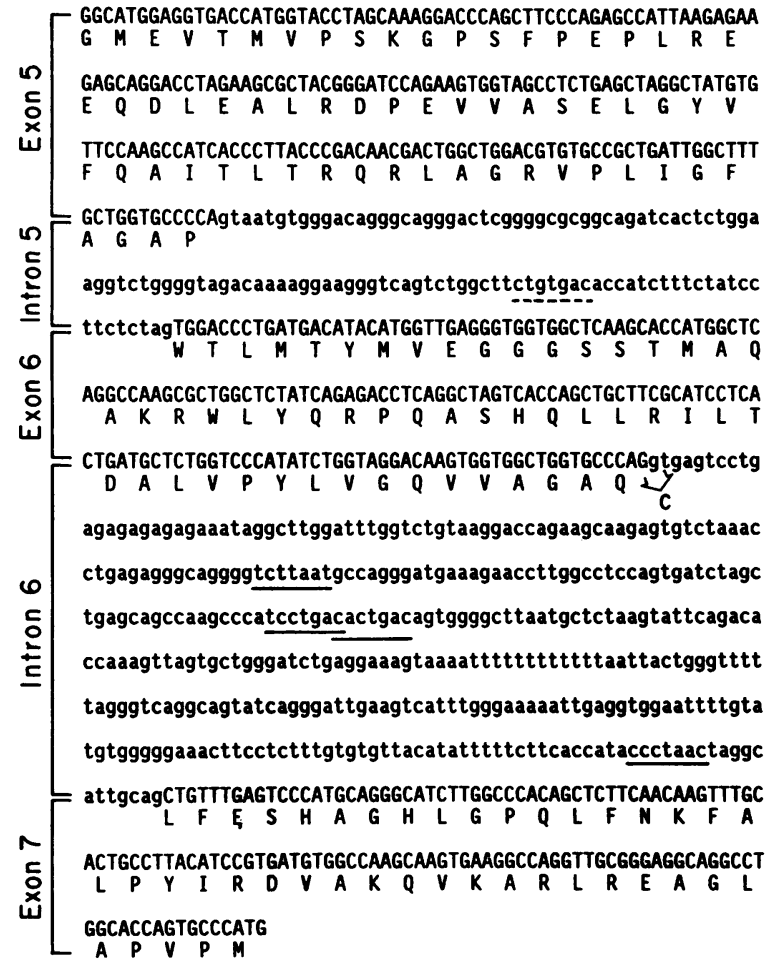

60

180 240 300 360 420 480 540 600 660 720 780 840

Figure 3. The sequence of a portion of the URO-D gene. Exon and intron locations are indicated on the left. Introns are in lower case and exons in uppercase. The arrow indicates the $\mathrm{G} \rightarrow \mathrm{C}$ mutation at the $5^{\prime}$ end of intron 6 (position 471). The most likely branch point sequence in intron 5 is indicated by the broken underlining. It differs from the consensus sequence at only one position and is followed by a polypyrimidine tract. All of the sequences that match the branch point consensus sequence in intron 6 are underlined. Numbering in this figure does not coincide with that used for the URO-D cDNA sequence.
In vitro translation was carried on RNA transcribed from pBluescript containing either the normal or the mutant cDNA sequence. Electrophoresis of the labelled in vitro translation products on $10 \%$ polyacrylamide gels revealed that the deleted cDNA produced a shortened URO-D protein (Fig. $4 A$ ). The normal and deleted cDNAs were cloned into the bacterial expression vector pKK233-2. Western blot analysis of lysates from bacteria expressing the normal and deleted cDNAs were found to produce the normal and shortened URO-D protein (Fig. $4 \mathrm{~B}$ ). To determine if the shortened URO-D was stable in the cell, we carried out two experiments. In the first, Western blots were carried out on lysates from lymphoblasts derived from affected and unaffected members of the pedigree using a rabbit anti-URO-D antibody. These showed that URO-D protein in affected individuals is roughly half that in normal individuals and no band was visible that corresponded to the mutant protein (Fig. $4 \mathrm{C}$ ). In the second experiment, in vitro translated ${ }^{35} \mathrm{~S}$-labeled normal and mutant URO-D proteins were exposed to lymphocyte lysates, aliquots removed every 4 $\mathrm{h}$ for $16 \mathrm{~h}$, and then subjected to electrophoresis on acrylamide SDS gels. The amount of URO-D remaining at each timepoint was determined by densitometry of the autoradiograms (Fig. 5). Linear regression analysis of the data indicated a half-life of $69 \mathrm{~h}$ for the normal protein and $19 \mathrm{~h}$ for the mutant protein.

Bacterially expressed normal and shortened URO-D proteins were assayed for URO-D catalytic activity using either uroporphyrinogen (octacarboxyl) or pentacarboxylporphyrinogen as substrates. The assay cannot distinguish between bac-

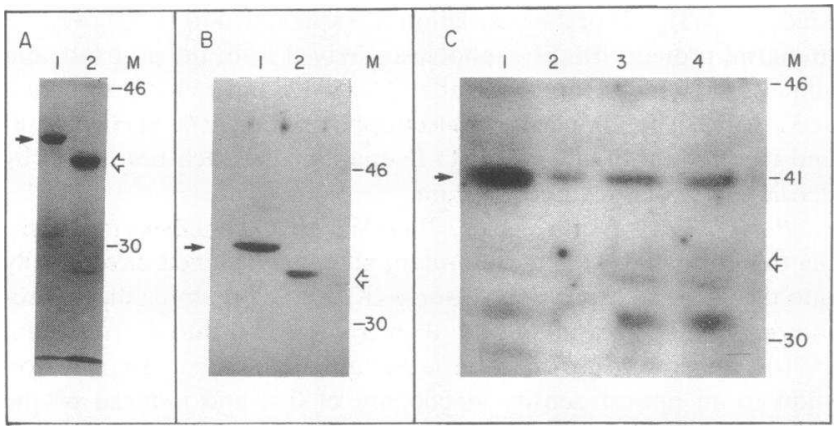

Figure 4. $(A)$ In vitro translation products of RNA derived from cloned normal and mutant URO-D cDNA. The radio-labeled products were run on a $10 \%$ SDS acrylamide gel and fluorographed. Lane 1 contains URO-D protein made from normal cDNA (solid arrow); lane 2 contains URO-D protein made from mutant CDNA (open arrow). Lane $M$ indicates the positions of molecular weight markers in kilodaltons. The bands nearest the bottom edge of the figure are unincorporated amino acids. $(B)$ Bacterially expressed normal and mutant URO-D were analyzed by Western blot. Lane 1 shows normal human URO-D (solid arrow), lane 2 shows mutant human URO-D (open arrow), and lane $M$ indicates the position of molecular weight markers in kilodaltons. $(C)$ Lymphocyte lysates from normal and affected individuals were subjected to Western blot analysis. The samples were normalized to equal total protein concentration. Lane 1 shows URO-D protein (solid arrow) from a normal individual; lanes 2-4 show URO-D protein from affected individuals. Lane $M$ indicates the position of molecular weight markers in kilodaltons. Open arrow indicates the expected position of the mutant protein. The fainter bands in the lower half of the gel may be URO-D degradation products and were seen in lysates from both normal and affected individuals. 


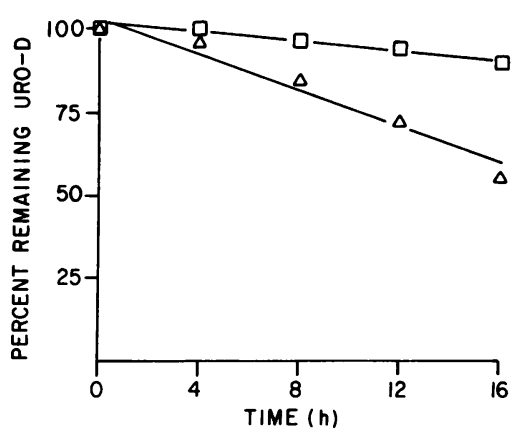

Figure 5. Results from in vitro degradation of normal and mutant URO-D (see Methods). The normal URO-D (squares) had a half-life of $69 \mathrm{~h}$, whereas the mutant (triangles) URO-D had a half-life of $19 \mathrm{~h}$ calculated by linear regression.

terial and human URO-D activity, so assays were also performed on bacterial lysates derived from cultures that did not have the expression vector. The normal length URO-D had significant levels of catalytic activity with both substrates, while the mutant URO-D protein had no activity with either substrate. The bacterial control also had no measurable activity (Fig. 6).

Dot blots of PCR amplified DNA from nine affected and two normal individuals of the pedigree and from 21 unrelated individuals with familial PCT were hybridized with an oligonucleotide probe that corresponded to the mutant DNA sequence. Results (Fig. $7 \mathrm{~A}$ ) indicated that all nine affected individuals from the pedigree had the same mutation. DNA from the two normal individuals did not hybridize to the mutant probe. DNA from affected members of four other unrelated PCT pedigrees hybridized to the mutant probe. The dot blots were stripped and rehybridized with a similar oligonucleotide probe that matched the normal sequence. This probe hybridized to all of the DNA samples (Fig. $7 \mathrm{~B}$ ), as expected in heterozygotes for a dominantly inherited trait. An internal control of cloned mutant genomic DNA was also dot blotted, and as expected, hybridized with the mutant probe but not the normal probe (Fig. 7).

\section{Discussion}

This is the first splice site mutation to be found at the URO-D locus. Previously described mutations at the URO-D locus have been point mutations in coding regions causing instability of the mutant URO-D protein $(8,9)$. An interesting feature of this splice site mutation is that an exon is deleted during splicing. The intron-exon junctions on either side of the miss-

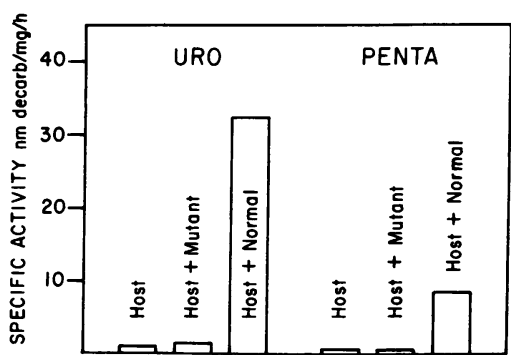

Figure 6. Result of assays of bacterially expressed normal (host + normal) and mutant (host + mutant) human URO-D with two different substrates. The left side indicates results using uroporphyrinogen I (URO) as the substrate, the right side

using pentacarboxyporphyrinogen I (PENTA). The bacterial negative controls (host) did not contain the plasmid with URO-D cDNA.

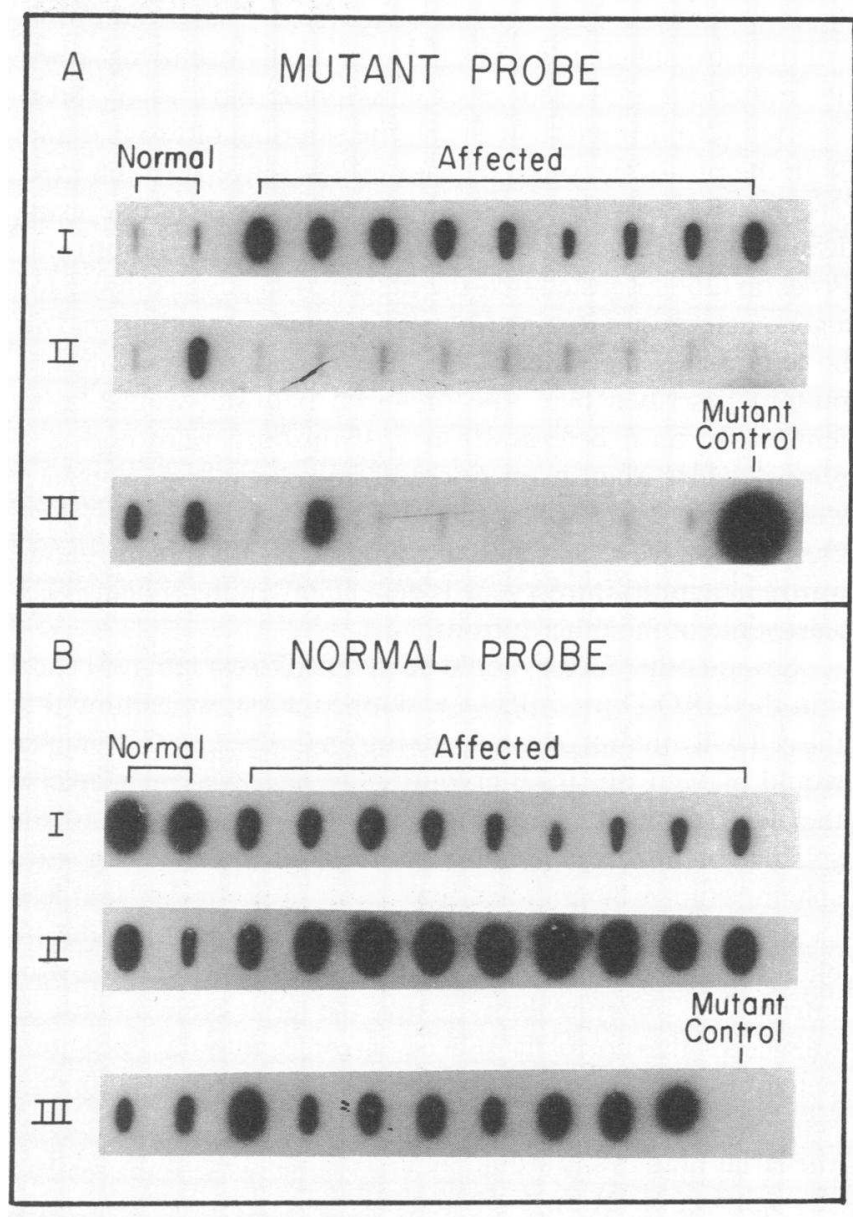

Figure 7. Slot blots of the PCR-amplified affected region of the URO-D gene. $A$ shows the blot hybridized with the mutant probe and $B$ shows the same blot hybridized with the normal probe. Row $I$ has DNA from normal and affected individuals of the original pedigree in which the mutation was found as indicated. Rows II and III are DNA from individuals from 21 other unrelated PCT pedigrees. Row III also contains cloned mutant genomic DNA as a control. As expected for a heterozygous mutant, all of the samples hybridized to the normal probe in $B$ except for the cloned mutant control, and positive signals in $A$ indicate individuals that contain the described mutation.

ing exon occur between codons, so the reading frame is maintained and the resulting protein matches the normal protein except for amino acids encoded by the missing exon. Most reported splice site mutations result in messages with frame shifts induced by unspliced introns or by new exon boundaries that no longer conserve the reading frame (23).

Some conclusions can be drawn about the URO-D splicing mechanism. Because the only aberrant cDNA observed was characterized by the absence of exon 6 , there are probably no usable cryptic splice sites in the affected region of the URO-D gene. Most reported splice site mutations, especially those of the globin genes, cause a nearby cryptic splice site to be used which results in mRNA that retains part of an intron or lacks part of an exon (24). Splice site sequence requirements have been studied extensively with in vivo and in vitro splicing systems $(23,25)$. Site directed mutagenesis of conserved sequences at the $5^{\prime}$ intron splice site have revealed that exon 
skipping rarely occurs with in vivo systems but is common with in vitro splicing systems (25). Naturally occurring splice site mutations that lead to exon skipping have rarely been reported (26). Mutations causing the skipping of exons 6 and 28 in the pro- $\alpha 2$ (I) collagen chain mRNA have been reported $(26,27)$. Each of these mutations caused an in-frame exon deletion which resulted in short, inactive proteins. Tromp and Prockop (26) suggested that the preferred splicing pathway for a gene determines if an exon will be skipped or an intron will be left in the aberrant mRNA. In the case of the URO-D mutant described here, the preferred pathway would be to remove intron 6 before intron 5 . If intron 5 were normally removed first, then exon 6 would be retained and intron 6 would likely fail to splice and remain in the mutant mRNA. Our data are consistent with the hypothesis that splicing of one intron in a multi-intron gene is dependent on the splicing of at least some of the other introns.

Several other factors could be invoked to explain how exon 6 in the URO-D pre-mRNA is skipped. First, we assume that the cell will attempt to splice out intron 6 . The $G \rightarrow C$ mutation would prevent this if no cryptic splice sites were available so the next splice attempt would be intron 5 . Why would the splicing of intron 5 include exon 6 and intron 6 ? In vitro splicing studies have shown that $5^{\prime}$ intron mutations that lead to skipping of the previous exon cause a superlariat that includes the preceding intron and exon as well as the following intron (25). One possibility is that the lariat branch point sequence of the normally spliced intron 5 may be "out-competed" by the branch point sequence in intron 6 . In the absence of the mutation, intron 6 would be spliced out first and the lariat branch site would be unavailable to compete during the splicing of intron 5. In the URO-D gene, there is no sequence in intron 5 that completely matches the consensus YNYURAY branch point sequence $(28,29)$ but several such sequences are present in intron 6 (Fig. 3). Branch point sequences are usually 18-37 nucleotides upstream from the $3^{\prime}$ splice site (28), but in some cases the branch point is much further away (30). In either case, the polypyrimidine tract is usually adjacent (downstream) to the branchpoint sequence. Intron 6 does not contain a polypyrimidine tract adjacent to any of the putative branch point sequences. Therefore, it is problematic to assign branch point sequences in either intron 5 or 6 based on sequence alone. Branch point sequences are not well conserved in higher eukaryotes, and site-directed mutagenesis of branch points have shown that deviating from the consensus branch point sequences does not completely inhibit splicing $(29,31)$. Some studies have shown that better consensus branch point sequences lead to more efficient splicing (29), which could explain our results.

The most important factor in determining the result of a 5 intron splice site mutation seems to be whether or not cryptic splice sites are present (23). If none are available, the possible effects of the mutation would be to leave the intron in or to include the preceding intron and exon in the lariat to form a superlariat, thus skipping the exon $(25,26)$. The next important factor may be the preferred splicing pathway (32). The normal order of splicing would determine if an exon were to be skipped. If the preceding intron were already removed, superlariat formation could not occur. If it had not yet been spliced then superlariat formation could occur possibly by branch point competition or some other mechanism (Fig. 8).

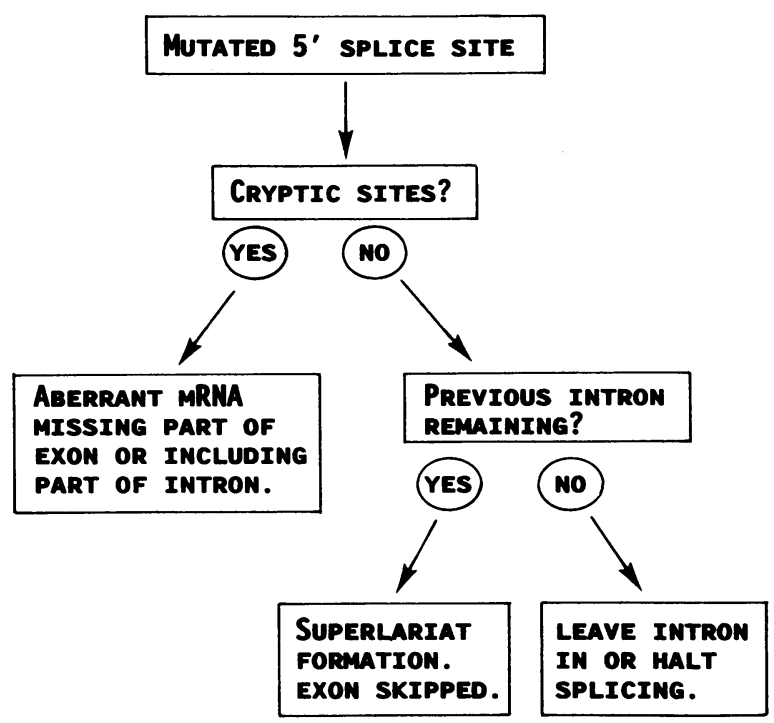

Figure 8. Proposed chain of events that show the result of various types of splice site mutations.

The amount of URO-D protein measured by immunoelectrophoresis in affected members of the pedigree described here was half normal, as was URO-D catalytic activity (11). However, the amount of URO-D mRNA measured by densitometry of Northern blots (11) was normal in affected pedigree members, indicating that the mutation does not affect the stability of the mRNA. The shortened protein is less stable in vitro than the normal protein, but it may be difficult to compare protein half lives measured in vitro with in vivo measurements. We have previously noted that the in vitro measurement of a mutant URO-D protein indicated an 8-h half-life of URO-D, whereas in vivo measurements from pulse-chase experiments in cultured lymphocytes indicated a much shorter half-life, substantially less than $4 \mathrm{~h}(9)$. Western blot analysis of lymphocyte lysates derived from affected pedigree members revealed that steady-state amounts of URO-D protein are about half that of normal members and there was no band corresponding to the mutant protein, indicating that steadystate levels of the mutant protein in vivo is very low. On the basis of our Western blots, previous immunoelectrophoresis experiments (11), and our in vitro measurements we conclude that the shortened protein is rapidly degraded in the cells.

The half-normal amount of URO-D enzyme does not explain the accumulation and excretion of uroporphyrin as URO-D is not the rate-limiting step in heme biosynthesis (33). Substrate accumulation is organ specific, occuring only in the liver, implying that URO-D does become rate limiting in hepatocytes of patients expressing the f-PCT clinical phenotype. The finding of half-normal activity of URO-D in liver biopsy specimens from patients with f-PCT may represent an artifact as the assay is carried out ex vivo with diluted liver homogenates. Under the assay conditions putative URO-D inhibitors (such as iron, porphyrins, or other compounds) would also be diluted. In patients clinically affected with f-PCT, one must assume that the product of the normal allele is inhibited by some unknown mechanism. This is illustrated by the observation that many carriers of defective URO-D alleles never develop clinical symptoms. 
The active site of URO-D is unknown although experiments with sulfhydryl-modifying agents indicate that cysteine residues may be involved (34). Kinetic data of purified bovine, chicken, and human URO-D suggest that there may be more than one active site, one catalyzing the initial decarboxylation of uroporphyrinogen and the others decarboxylating intermediates leading to the final product, coproporphyrinogen (34-36). We measured catalytic activity of the shortened URO-D with two different substrates to determine if the mutant protein could decarboxylate one substrate but not another. The results indicate that the shortened protein cannot decarboxylate uroporphyrinogen or pentacarboxyporphyrinogen. The deletion of 54 amino acids from URO-D could significantly alter the tertiary structure of the protein, so it is not surprising to find a total loss of catalytic activity. We can draw no conclusions about the number or position of the active site(s) from our results.

This is the first mutation responsible for PCT to be found in more than one pedigree. It was found in five of 22 pedigrees tested. Most of these pedigrees were collected in a single geographic region of the United States. It is possible that at least some of the pedigrees are related, but no evidence of this was found in their family histories. Homozygous defects at the URO-D locus have been shown to cause HEP, a very rare (17 cases reported worldwide as of 1987 , reference 37) disease. The mutation causing HEP that has been characterized to date produced unstable but active URO-D (8) so that some residual steady-state catalytic activity remained. The splice site mutation we have described would probably not be found in a homozygous state because the mutant gene product is totally inactive, and homozygosity would be lethal. If the majority of f-PCT cases are caused by splice-site mutations with a similar effect, then this would explain the rarity of reported HEP.

\section{Acknowledgments}

We thank Dr. Stephen Elbein for productive discussions and Dr. Brenda Bass for useful comments about the manuscript.

This work is supported by grants DK20503, DK07115, and RR00064 from the National Institute of Health.

\section{References}

1. Jackson, A. H., H. A. Sancovich, A. M. Ferramola, N. Evans, D. E. Games, S. A. Matlin, G. H. Elder, and S. G. Smith. 1976. Macrocyclic intermediates in the biosynthesis of porphyrins. Phil. Trans. R. Soc. Lond. Ser. B. 273:191-206.

2. Barnard, G. F., and M. Akhtar. 1979. Stereochemical and mechanistic studies on the decarboxylation of uroporphyrinogen III in haem biosynthesis. J. Chem. Soc. Perkin Trans. I. 2354-2359.

3. deVerneuil, H., S. Sassa, and A. Kappas. 1983. Purification and properties of uroporphyrinogen decarboxylase from human erythrocytes. A single enzyme catalyzing the four sequential decarboxylations of uroporphyrinogens I and III. J. Biol. Chem. 258:2454-2460.

4. Smith, A. G., and J. E. Francis. 1981. Investigations of rat liver uroporphyrinogen decarboxylase. Biochem. J. 195:241-250.

5. Romeo, P.-H., N. Raich, A. Dubart, D. Beaupain, M. Pryor, J. Kushner, M. Cohen-Solal, and M. Goossens. 1986. Molecular cloning and nucleotide sequence of a complete human uroporphyrinogen decarboxylase cDNA. J. Biol. Chem. 261:9825-9831.

6. Romana, M., A. Dubart, D. Beaupain, C. Chabret, M. Goossens, and P.-H. Romeo. 1987. Structure of the gene for human uroporphyrinogen decarboxylase. Nucleic Acids Res. 15:7343-7356.
7. Kushner, J. P., A. J. Barbuto, and G. R. Lee. 1976. An inherited enzymatic defect in porphyria cutanea tarda. J. Clin. Invest. 58:10891097.

8. deVerneuil, H., B. Grandchamp, C. Beaumont, C. Picat, and Y. Nordmann. 1986. Uroporphyrinogen decarboxylase structural mutant $\left(\mathrm{gly}^{281} \rightarrow \mathrm{glu}\right.$ ) in a case of porphyria. Science (Wash. DC). 234:732-734.

9. Garey, J. R., J. L. Hansen, L. M. Harrison, J. B. Kennedy, and J. P. Kushner. 1989. A point mutation in the coding region of uroporphyrinogen decarboxylase associated with familial porphyria cutanea tarda. Blood. 73:892-895.

10. deVerneuil, H., J. Hansen, C. Picat, B. Grandchamp, J. Kushner, A. Roberts, G. Elder, and Y. Nordmann. 1988. Prevalence of the 281 (Gly $\rightarrow$ Glu) mutation in hepatoerythropoeitic porphyria and porphyria cutanea tarda. Hum. Genet. 78:101-102.

11. Hansen, J. L., M. Pryor, J. B. Kennedy, and J. P. Kushner. 1988. Steady state levels of uroporphyrinogen decarboxylase mRNA in lymphoblastoid cell lines from patients with familial porphyria cutanea tarda and their relatives. Am. J. Hum. Genet. 42:847-853.

12. Huynh, T. V., R. A. Young, and R. W. Davis. 1985. Constructing and screening $\mathrm{cDNA}$ libraries in lambda gt 10 and lambda gt 11 . In DNA Cloning. Vol. I. A Practical Approach. D. M. Glover, editor. IRL Press, New York. 49-78.

13. Saiki, R. K., D. H. Gelfand, S. Stoffel, S. J. Scharf, R. Higuchi, G. T. Horn, K. B. Mullis, and A. Erlich. 1988. Primer-directed enzymatic amplification of DNA with a thermostable DNA polymerase. Science (Wash. DC) 239:487-491.

14. Sanger, F., S. Nicklen, and A. R. Coulson. 1977. DNA sequencing with chain-terminating inhibitors. Proc. Natl. Acad. Sci. USA. 74:5463-5467.

15. Maniatis, T., E. F. Fritsch, and J. Sambrook. 1982. Molecular Cloning. A Laboratory Manual. Cold Spring Harbor Press, Cold Spring Harbor, NY. 545 pp.

16. Feinburg, A. P., and B. Vogelstein. 1983. A technique for radiolabeling DNA restriction endonuclease fragments to high specific activity. Anal. Biochem. 132:6-13.

17. Melton, D. A., P. A. Krieg, M. R. Rebagliati, T. Maniatis, K. Zinn, and M. R. Green. 1984. Efficient in vitro synthesis of biologically active RNA and RNA hybridization probes from plasmids containing a bacteriophage SP6 promotor. Nucleic Acids Res. 12:70357056.

18. Laemmli, U. K. 1970. Cleavage of structural proteins during the assembly of the head of bacteriophage T4. Nature (Lond.). 227:680-685.

19. Straus, D., and W. Gilbert. 1985. Chicken triosephosphate isomerase complements an Escherichia coli deficiency. Proc. Natl. Acad. Sci. USA. 82:2014-2018.

20. Burnette, W. N. 1981. "Western blotting": electrophoretic transfer of proteins from sodium dodecyl sulfate-polyacrylamide gels to unmodified nitrocellulose and radiographic detection with antibody and radioiodinated protein A. Anal. Biochem. 112:195-203.

21. Straka, J. G., J. P. Kushner, and M. A. Pryor. 1982. Uroporphyrinogen decarboxylase: a method for measuring enzyme activity. Enzyme (Basel). 28:170-185.

22. Smith, P. K., R. I. Krohn, G. T. Hermanson, A. K. Mallia, F. H. Gartner, M. D. Provenzano, E. K. Fujimoto, N. M. Goeke, B. J. Olson, and D. C. Klenk. 1985. Measurement of protein using bicinchoninic acid. Anal. Biochem. 150:76-85.

23. Padgett, R. A., P. J. Grabowski, M. M. Konarska, S. Seiler, and P. A. Sharp. 1986. Splicing of messenger RNA precursors. Annu. Rev. Biochem. 55:1119-1150.

24. Bunn, H. F., and B. G. Forget. 1986. Hemoglobin: molecular, genetic and clinical aspects. W. B. Saunders Co., Philadelphia. 690 pp.

25. Aebi, M., H. Hornig, R. A. Padgett, J. Reiser, and C. Weissmann. 1986. Sequence requirements for splicing of higher eukaryotic nuclear pre-mRNA. Cell. 47:555-565.

26. Tromp, G., and D. J. Prockop. 1988. Single base mutation in the proa2(I) collagen gene that causes efficient splicing of RNA from 
exon 27 to exon 29 and synthesis of a shortened but in-frame pro $\alpha 2(I)$ chain. Proc. Natl. Acad. Sci. USA. 85:5254-5258.

27. Weil, D., M. Bernard, N. Combates, M. K. Wirtz, D. W. Hollister, B. Steinmann, and F. Ramirez. 1988. Identification of a mutation that causes exon skipping during collagen pre-mRNA splicing in an Ehlers-Danlos syndrome variant. J. Biol. Chem. 263:8561-8564.

28. Smith, C. J., E. B. Porro, J. G. Patton, and B. Nadal-Ginard. 1989. Scanning from an independently specified branch point defines the 3 ' splice site of mammalian introns. Nature (Lond.). 342:243-247.

29. Zhuang, Y., A. M. Goldstein, and A. M. Weiner. 1989. UACUAAC is the preferred branch site for mammalian mRNA splicing. Proc. Natl. Acad. Sci. USA. 86:2752-2756.

30. Helfman, D. M., and W. M. Ricci. 1989. Branch point selection in alternative splicing of tropomyosin pre-mRNAs. Nucleic Acids Res. 17:5633-5650.

31. Reed, R., and T. Maniatis. 1988. The role of the mammalian branchpoint sequence in pre-mRNA splicing. Genes \& Dev. 2:12681276.
32. Lang, K. M., and R. A. Spritz. 1987. In vitro splicing pathways of pre-mRNAs contain multiple intervening sequences. Mol. Cell. Biol. 7:3428-3437.

33. Bishop, D. F., and R. J. Desnick. 1982. Preface. Enzyme (Basel). 28:91-93.

34. Elder, G. H., J. A. Tovey, and D. M. Sheppard. 1983. Purification of uroporphyrinogen decarboxylase in porphyria cutanea tarda from human erythrocytes. Biochem. J. 215:45-55.

35. Straka, J. G., and J. P. Kushner. 1983. Purification and characterization of bovine hepatic uroporphyrinogen decarboxylase. Biochemistry. 22:4664-4672.

36. Kawanishi S., Y. Keki, and S. Sano. 1983. Uroporphyrinogen decarboxylase: purification, properties, and inhibition by polychlorinated biphenyl isomers. J. Biol. Chem. 258:4285-4292.

37. Toback, A. C., S. Sassa, M. B. Poh-Fitzpatrick, J. Schecter, E. Saider, L. C. Harber, and A. Kappas. 1987. Hepatoerythropoietic porphyria: clinical, biochemical, and enzymatic studies in a three generation family lineage. N. Engl. J. Med. 316:645-650. 